\author{
Melanie Wielicka*(D), Jolanta Neubauer-Geryk*(D), Grzegorz Kozera ${ }^{\mathbb{D}}$, Leszek Bieniaszewski(D) \\ *Both authors had an equal authorship in the study \\ Clinical Physiology Unit, Medical Simulation Centre, Medical University of Gdansk, Gdansk, Poland
}

\title{
Clinical application of pulsatility index
}

\author{
Corresponding author: \\ Jolanta Neubauer-Geryk, Clinical \\ Physiology Unit, Medical Simulation \\ Centre, Medical University of Gdansk, \\ Gdansk, Poland, Dębowa 25 Str. \\ 80-204 Gdansk, Poland \\ e-mail: jolaneub@gumed.edu.pl
}

\begin{abstract}
Pulsatility index $(\mathrm{PI})$ is defined as the difference between the peak systolic flow and minimum diastolic flow velocity, divided by the mean velocity recorded throughout the cardiac cycle. It is a non-invasive method of assessing vascular resistance with the use of Doppler ultrasonography. It was first introduced in 1974 by Gosling and King and is also known as the Gosling Index. PI as a method of examining macrocirculation has a variety of clinical applications. For instance, in diabetic patients, it has been measured on the common carotid, middle cerebral or renal arteries to help predict complications such as cerebrovascular disease or nephropathy. In hypertensive patients, it has been used to assess complications and assess the chronicity of the disease. To our knowledge, despite the diverse use of this ultrasonographic parameter, there is a deficiency in reports that would comprehensively summarize its clinical applications.

Based on our extensive review of the literature and the gathered information, we conclude that pulsatility index $(\mathrm{PI})$ is an easy to obtain parameter with a broad range of both, research and clinical applications. It has been widely used in the assessment of macrocirculation in highly prevalent chronic medical conditions, such as hypertension, both type 1 and type 2 diabetes and thyroid disorders.

Key words: pulsatility index, clinical application, cerebral artery, carotid artery, renal artery
\end{abstract}

Med Res J 2020; 5 (3): 201-210
Medical Research Journal 2020;

Volume 5, Number 3, 201-210

.5603/MRJ.a2020.0016

ISSN 2451-2591

\section{Introduction}

Macrovascular complications, such as cardiovascular and cerebrovascular events, are the leading cause of mortality in patients with common vascular risk factors, such as diabetes or hypertension. It is estimated that, globally, approximately $32.2 \%$ of type $2,30.3 \%$ of type 1 diabetic and $30 \%$ hypertensive patients suffer from cardiovascular complications [1-5].

Pulsatility is an intrinsic property and an integral aspect of the cardiovascular system, strongly related to elasticity of arteries. The natural pulsations in pressure caused by each contraction of the left ventricle are largely diminished thanks to elasticity of large arteries. As the aorta expands, it stores a portion of the stroke volume, so that the microvasculature is less exposed to pulsatile stress [6]. Thus, the elasticity of blood vessels allows for blunting down harmful pulsations in the large arteries before they reach end-organ microcirculation [6]. However, from early on in childhood, arterial walls continually increase in stiffness through the loss of elastic fibers. This process is further augmented by disorders of metabolism such as hyperlipidemia or diabetes mellitus through a variety of mechanisms. A decrease in elasticity is associated with a multitude of complica- tions, including increased stress on the left ventricle, a gradual increase in blood pressure and, eventually, even end-organ damage through the transmission of harmful pulsation into the microcirculation. Thus, the increase in pulsatility associated with loss of elastic recoil in large blood vessels has detrimental effects on global cardiovascular health.

Pulsatility index (PI) is defined as the difference between the peak systolic flow and minimum diastolic flow velocity, divided by the mean velocity recorded throughout the cardiac cycle. It is a non-invasive method of assessing vascular resistance with the use of doppler ultrasonography. It was first introduced in 1974 by Gosling and King, thus is also known as the Gosling Index [7, 8]. Due to the vast applications of this parameter, we comprehensively discuss $\mathrm{PI}$ use and its clinical significance in the assessment of microcirculatory system (Fig. 1).

\section{Macrocirculation and pulsatility}

The great physiological and clinical significance of arterial pulsatility is related to how the large, elastic arteries serve as a type of reservoir that functions to 


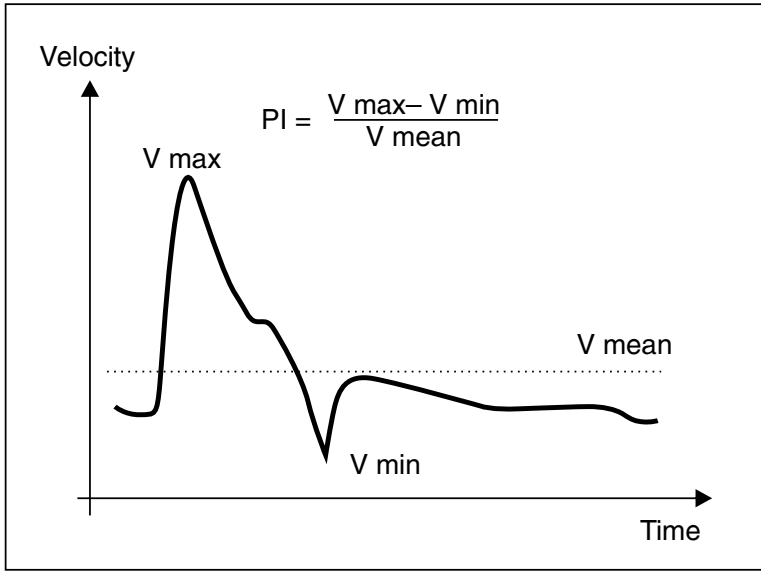

Figure 1. Calculation of the Pulsatility (Gosling) Index (PI). $\mathrm{V}$ max - maximal flow velocity, $\mathrm{V}$ min - minimal flow velocity, $\mathrm{V}$ mean - mean flow velocity

store blood during systole and expel it to the peripheral circulation during diastole within each contraction of the left ventricle $[4,5]$. This provides a constant flow of blood into the microvascular beds throughout the cardiac cycle, allowing for continuous exchange of substances between tissues and plasma. Loss of this elastic reservoir has several negative effects on the cardiovascular system and has the potential to damage end-organ circulation. With the loss of elasticity, there is an increase in pulsatile load of the heart, which has detrimental effects on the left ventricle through increasing its mass and thus the myocardial oxygen demand [9]. Additionally, the increased pulsations resulting from the stiffness of large vessels are believed to affect the capillary networks, resulting in microvascular complications, as they allow the harmful pulsations to be conducted into end-organ microcirculation [10]. This is particularly important when it comes to organs characterized by high flow and low resistance, such as the brain and the kidneys [6].

The complex elastic fiber mesh in large blood vessels begins its synthesis development in early embryogenesis, a process which continues up until early childhood. As a result, adults have a relatively fixed amount of elastic fibers in their aorta, which slowly stretch out, degenerate and become replaced by much less compliant collagen fibers [9]. As shown by Eberth et al increasing pulsatile pressure and continuous flow injury on the vascular wall result in a significant increase in the number of cells and an increased collagen-to-elastin ratio with further aortic wall thickening and luminal narrowing [11]. The progression of arterial stiffening and the increase in flow pulsatility in the elderly occurs due to the fact that the less elastic vessels are no longer capable of buffering the flow pulsations generated with each ventricular contraction.
The impact of aging on arterial stiffness and pulsatility has been demonstrated in several studies. Zarrinkoob et al [12] investigated how age and sex impacts the dampening of the pulsatile flow from the proximal to the distal cerebral arteries. The study groups consisted of 45 healthy elderly, with a mean are of 71 years, and 49 young healthy subjects, with a mean age of 25 years. The authors found that especially cerebral pulsatile flow was dampened from proximal to distal parts of the cerebral arterial system and that this dampening was more pronounced in the younger studied group. This demonstrates how aging impacts the ability of larger, more elastic arteries to diminish delivery of harmful pulsations to smaller blood vessels. Several other authors have also shown an increase in $\mathrm{PI}$ of the cerebrovascular circulation with an increase in age $[13,14]$. Additionally, Schoning et al $[15,16]$ used ultrasound examination to establish $\mathrm{PI}$ at the common carotid artery in healthy children, adolescents and adults. They were able to demonstrate how arterial hemodynamics change with age and show that $\mathrm{PI}$ is an age-dependent parameter.

It is also worth mentioning how an increase in arterial diameter affects $\mathrm{PI}$. It has been described that in arterial aneurysms, a Windkessel effect takes place, where the aneurysm acts as a reservoir for blood during systole and releases it during diastole. This results in lower pulse pressure, because of increased vascular resistance distally $[9,10]$. This was supported by a study by Hussein et al [9], where the authors demonstrated the relationship between the size of internal carotid artery aneurysms and distal intracranial hemodynamics. They have measured flow and pulsatility index within bilateral middle cerebral arteries and internal carotid arteries prior to initiating any treatment. They found that larger aneurysmal size $(>10 \mathrm{~mm})$ had a significant correlation with higher ipsilateral middle cerebral artery $\mathrm{PI}$. Conversely, a decrease in aortic diameter causes an increase in vascular resistance. An increase in pulsatility index is a reliable marker of distal resistance in the examined blood vessel [11]. Pulsatility index as a measure of vascular resistance has also been used in examining patients with carotid artery stenosis as well as aortic stenosis, helping in assessment of the efficacy of treatment.

$\mathrm{PI}$ as a method of examining macrocirculation has a wide range of clinical applications. For instance, in diabetic patients it has been measured on the common carotid, middle cerebral or renal arteries to help predict complications such as cerebrovascular disease or nephropathy $[12,13]$. In hypertensive patients, it has been used to assess complications and assess the chronicity of disease [14]. To our knowledge, despite the diverse use of this ultrasonographic parameter, there is a deficiency in reports that would comprehen- 
sively summarize its clinical applications. Thus, we would like to discuss the value of pulsatility index in the macrovascular examination.

\section{Clinical applications of PI}

\section{Pulsatility index in hypertension and heart disease}

Many available reports discuss the association between the loss of arterial elasticity and hypertension. A study by Clime et al explains that increased blood pressure values are associated with an increase in intimal-media thickness, lumen enlargement and increased stiffness of proximal elastic arteries [6]. Conversely, Mitchell discusses several publications that have shown that the arterial stiffness precedes and strongly contributes to the development of hypertension [9].

In hypertensive patients, the pulsatility index can be used as a predictor of complications and help assess chronicity of disease. Cho et al measured flow velocities and Gosling Index of the middle cerebral and internal carotid arteries in 94 hypertensive patients. They demonstrated a significant decrease in flow velocities, and an increase in the Gosling index in patients who had hypertension for over five years. These differences were not present in patients with a shorter duration of the disease [14].

PI has also been studied in patients with renovascular hypertension, and hypertension associated with renal failure. A report by Bardelli et al discusses the possible use of the pulsatility index of renal arteries as an indicator of bilateral renal artery stenosis in hypertensive patients. They were able to correctly diagnose renovascular hypertension in $84 \%$ of patients, while the presence of renal artery stenosis was established in $94 \%$ of patients [16]. Renal artery PI and resistive index have also been demonstrated to be associated with renal function parameters, such as creatinine clearance, in patients with renal failure and hypertension [17]. Additionally, Okuma et al studied intrarenal PI and resistive index in patients with hypertension and showed that they are positively correlated with carotid intima-media thickness, suggesting that those measurements could be used in the evaluation of arterial stiffness in hypertensive patients [18].

In a recently published study from 2019 , Sasaki et al have shown that common carotid artery $\mathrm{PI}$, as well as resistance index measurements, are associated with the log NT-pro-BNP levels in hypertensive patients, suggesting that PI could be a useful marker of hemodynamic stress on the left ventricle, while mean intima-media thickness, number of plaques and plaque score had no association with log NT-proBNP [19].

\section{Pulsatility index in atherosclerosis and arterial stenosis}

Several studies report a relationship between pulsatility and atherosclerotic disease. Pulsatility index has been studied as an additional parameter when assessing arterial wall shear stress, an important predictor of cardiovascular risk and atherosclerosis development. Avrahami et al have studied pulsating flow waveforms in a straight, rigid tube, with and without flow reversals. Their results had indicated that adding $\mathrm{PI}$ to the already widely used average flow rate and heart rate measurements improve diagnostic evaluation [20]. Jotoku et al. have shown a significant association between pulsatility index of the common carotid artery with cardiovascular risk factors, namely homocysteine and monocyte levels. Both of the latter parameters have been shown to be related to coronary plaque development and progression in acute myocardial infarction [21].

As per Poiseuille's Law, a decrease in vascular diameter, such as in the case of arterial stenosis, leads to an increase in vascular resistance [22]. An increase in PI is a reliable marker of distal resistance in the examined blood vessel [11], which is why it can be useful in assessing the distal parts of examined vessels that are not as easily accessible with ultrasound techniques. Thus, the pulsatility index as a measure of vascular resistance has been utilized in assessing arterial narrowing and efficacy of treatment in carotid artery stenosis. Heyer et al [23] studied PI of the middle cerebral artery in patients with carotid artery stenosis and its correlation with cerebral blood flow and cognitive function post carotid endarterectomy. The authors explained that those patients frequently have reduced cerebral vascular resistance, likely through autoregulation, to compensate for decreased cerebral blood flow, with PI values in symptomatic patients typically documented to be $<1.0$. They found that symptomatic patients with a low baseline $\mathrm{PI}(=<0.80)$ are likely to have increased cerebral blood flow and improved cognitive function even 1 day after carotid endarterectomy.

Wada et al [24] investigated whether carotid ultrasonography indices could help detect the progression of arterial stenosis in patients with vertebral artery (VA) dissection. In patients admitted with intracranial VA dissection, an MR angiography (MRA) was performed at admission and after a median of 20 days, while the baseline peak systolic velocity, end-diastolic velocity, mean velocity and pulsatility index were measured at admission and followed up after a median of 22 days. A follow up to baseline ratio was then calculated. The PI ratio was significantly higher in patients with stenosis progression, while there were no significant differences in the other measured parameters. The authors concluded 


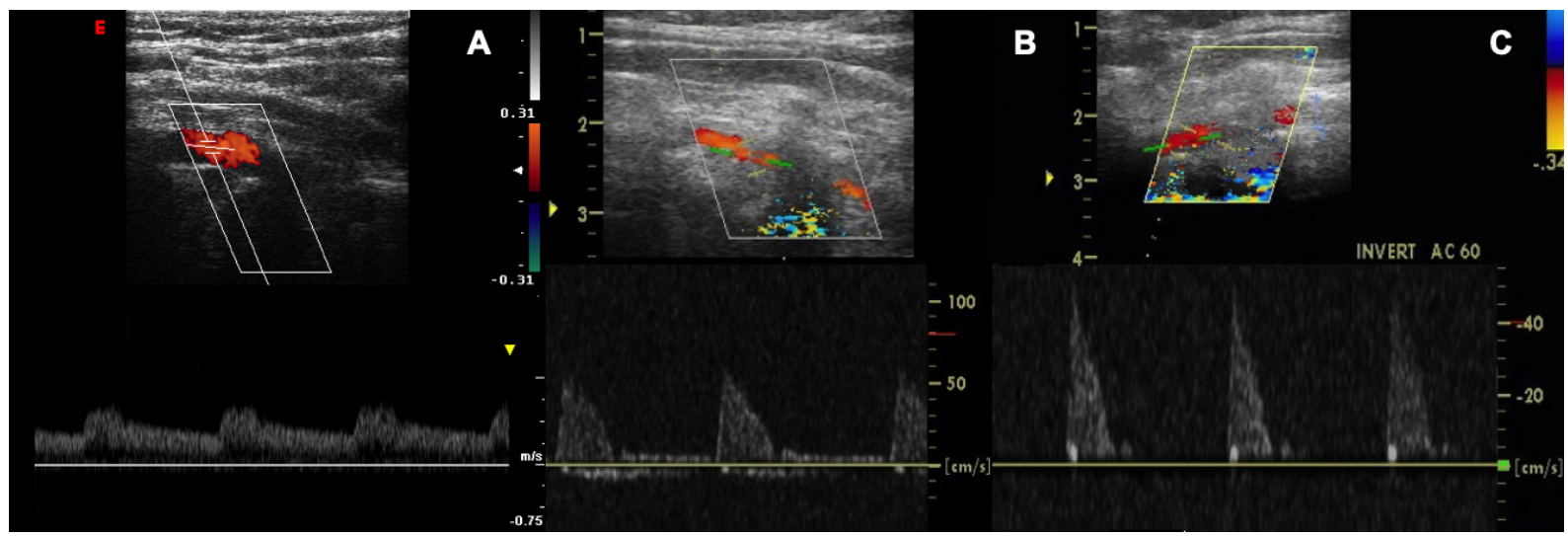

Figure 2. Extra-cranial Doppler Duplex examination of vertebral artery. A - normal flow pulsatility; B - increased pulsatility due to distal occlusion with preserved collateralization by Posterior Inferior Cerebellar Artery; C - increased pulsatility due to distal occlusion without preserved collateralization by Posterior Inferior Cerebellar Artery. AC - angle correction [The exam performed at the Laboratory of Neurosonology of the Department of Neurology, Collegium Medicum in Bydgoszcz, Nicolaus Copernicus University in Toruń, head of the clinic dr. hab. G. Kozera, ESAOTE MyLab Class C apparatus with a $5.5 \mathrm{MHz}(\mathrm{A})$ linear probe and in the Laboratory of Neurosonology of the Clinic of Neurology, Medical University of Gdańsk, head of the clinic prof. W. M. Nyka, GE Vivid I device with $5.5 \mathrm{MHz}$ linear probe (B-C)]

that PI might be a useful index in the detection of arterial stenosis progression. Thus, an increase in PI may be currently used as an ultrasonographic marker of distal stenosis or occlusion and help to predict its site (Fig. 2).

$\mathrm{PI}$ has also been used in patients with age-related aortic stenosis. Cay et al investigated the association between ascending aortic pressure-derived indices and hemodynamic characteristics of calcific aortic stenosis (AS) [25]. They measured fractional pulse pressure (FFP) and pulsatility index in the ascending aorta in a group of patients with aortic stenosis and healthy controls. Both values were significantly higher in the AS group. The authors suggested future studies could potentially evaluate the prognostic value of both FFP and $\mathrm{PI}$ in determining the severity of calcific aortic stenosis.

\section{Pulsatility index in vascular malformations}

In neurosurgery, $\mathrm{PI}$ is helpful in the evaluation of cerebral arteriovenous malformations (AVMs). The feeding arterioles in AVMs empty directly into a vein with no capillary network in between to increase resistance. This has been associated with high-flow and low resistance within the ACMs, with a decrease in PI values [26]. Burkhardt et al. have analyzed hemodynamic profiles, measured flow velocities, resistance index and pulsatility index of feeding and draining arteries in 32 patients with AVMs with the use of intraoperative micro-Doppler (IOMD). They concluded that IOMD is a safe and useful tool which helps in eliminating only the necessary blood vessels and that $\mathrm{PI}$ and $\mathrm{Rl}$ are reliable in diagnosing cerebrovascular malformations [27].

Kaspera et al. studied the impact of treatment on hemodynamic parameters of AVMs using color-coded doppler sonography. They assessed mean flow velocity, pulsatility index and vasomotor reactivity in the major cerebral vessels in 46 adult patients who were all diagnosed with AVMs. These parameters were recorded at admission, within 24 hours after the first embolization or surgical resection, and before the second embolization. The authors found a decrease in mean flow velocity and an increase in $\mathrm{Pl}$ in the embolized feeding vessels [28].

\section{Pulsatility index in diabetes}

According to the CDC statistics, there were in total of 26.9 million diagnosed cases of diabetes in the United States in 2018 alone, with only $5.2 \%$ of these cases accounted for by type 1 diabetes [29]. Long-standing hyperglycemia in diabetic patients is known to damage the vascular endothelium, and correlates with an increase in vascular stiffness [30], increasing pulsations. The increased pulsations resulting from the stiffness of large vessels are also believed to affect the capillary networks, resulting in microvascular complications [31]. Thus, several studies have shown a possible application for the pulsatility index in examining the larger blood vessels to predict and prevent microvascular complications in diabetic patients, especially in the renal and cerebral circulation. 
In a study from 2006, pulsatility index at the internal carotid artery was used to indicate presence of microangiopathy by showing its strong correlation with microalbuminuria in type 2 diabetic patients [32]. A different, more recent study from 2018 , has determined the relationship between renal resistivity index, pulsatility index and renal function parameters, namely urinary albumin secretion rate, serum creatinine levels and eGFR (estimated glomerular filtration rate). The positive correlation between $\mathrm{PI}$, albuminuria and serum creatinine, combined with a negative correlation with eGFR, suggest that PI may be a useful parameter in predicting renal dysfunction in type 2 diabetic patients [13].

Lee at al. have shown that pulsatility index at the middle cerebral artery and at the internal carotid artery was significantly higher in patients with microvascular complications such as retinopathy, nephropathy and neuropathy than those with no complications and healthy controls. Their study population consisted of 56 types 2 diabetic patients, with a mean age of 59 , and 70 age-and gender-matched controls [33]. Agha et al have measured pulsatility index along with flow velocity at the middle cerebral, basilar and intracranial portion of the internal carotid artery in a large sample of 141 of diabetic patients and 131 age and sex-matched controls. Their results have demonstrated a statistically significant difference between these values when they compared patients with diabetes to healthy controls. When dividing the diabetic group into patients with or without complications, they were also able to demonstrate significant differences between those two sub-groups. They had concluded that arterial pulsatility index can be used as an indicator of the presence of cerebral microangiopathy in type 2 diabetic patients [34]. A different study on cerebrovascular pulsatility in diabetes investigated the relationship between insulin resistance and pulsatility index in diabetic patients by measuring the PI at middle cerebral artery [35]. The authors found that pulsatility index was significantly higher in diabetic patients when compared to healthy controls, and additionally, was also higher in patients who had insulin resistance confirmed with a short insulin tolerance test, than in patients with diabetes alone. However, it is important to note that the age and duration of diabetes independently contributed to the changes in PI between the subgroups. Kozera et al. studied the presence of cerebral and skin angiopathy in adult patients with type 1 diabetes mellitus. In a group of adult patients with type 1 diabetes mellitus, authors found no significant association between cerebral and skin microvasculature function despite the simultaneous presence of cerebral microangiopathy reflected by increased $\mathrm{PI}$ of the middle cerebral artery and skin microangiopathy (reflected in by increased COVERAGE of skin capillaries)[36]. Kozera et al. also showed that the presence of asymptomatic brain injury (white matter lesions, WML) may be related to higher PI in the presence of additional confounders, such as type 2 diabetes and ACE inhibitor or statin use [37].

The decline in peripheral vascular function is also an important complication of diabetes. In 2005, Janssen suggested pulsatility index as a non-invasive method of evaluation of critical limb ischemia in patients with diabetic neuropathy. This study even compares PI to ankle-brachial doppler index and the systolic ankle pressure, and shows that it is superior to the other methods when assessing critical limb ischemia in this group of patients [38]. In a study by Zou et al, the authors explored the clinical value of ultrasound examination combined with a warm bath in the assessment of the microcirculation in diabetic patients. Several Doppler parameters were used, including pulsatility and resistivity indices at the dorsalis pedis artery and plantar digital artery. They suggested that color doppler combined with a warm bath test could potentially be used when assessing the differences in reactivity of distal limb microvasculature in patients with type 2 diabetes [13].

Additionally, the pulsatility index has been used to help assess the effects of certain therapies in diabetic patients. A study from 2016 used PI to analyze the effect of Naoxitong Capsules on vascular remodelling of carotid artery in type 2 diabetic patients [39]. In another report by Park et al. the effect of pioglitazone on the pulsatility index of cerebral arteries and carotid intima thickness in type 2 diabetic patients was studied. The study group involved 40 types 2 diabetic patients, divided into two groups: one treated with pioglitazone and one treated with gliclazide. Pulsatility index was calculated for each group based on transcranial Doppler examination and was found to be significantly decreased in the pioglitazone treated group. Through obtaining the PI measurements, the authors were able to conclude that pioglitazone improved cerebrovascular resistance in type 2 diabetic patients [40].

\section{Pulsatility index in children}

In healthy subjects, $\mathrm{PI}$ is an age-dependent parameter. This fact was described by Schoning et al [41, 42] in their studies applying ultrasound examination of PI for common carotid artery in healthy children, adolescents and adults. They showed that PI changes from value $1.73 \pm 0.31$ for children under 10 years of age through $1.97 \pm 0.42$ in children and adolescents over 10 years of age [41] to $1.72 \pm 0.5$ for adults [41, 42]. The significant differences of $\mathrm{PI}$ between groups were shown. It is worth noticing that according to Shoning et al., pulsatility index at common carotid in adults artery significantly decreases with age $(r=-0,52, p=0.001)$ [42]. 
Pulsatility index, being a fast, simple and non-invasive test that does not require a lot of cooperation, has many applications in the pediatric population. For instance, it has been used to evaluate renal vasculature in type 1 diabetic children. A study from 2010 has investigated renal resistive index as well as pulsatility index in a large sample of 100 diabetic children, aged $13.4 \pm 2.9$ years, with an average diabetes duration $7.2 \pm 2.5$ years, as well as in 30 healthy controls. Both pulsatility Index (mean PI left/right in diabetic patients $1.15 \pm 0.2$, mean PI left/right in healthy controls $1.0 \pm 0.1, p=0.04$ ) and Resistivity Index (mean RI left/right in diabetic children $0.72 \pm 0.1$, mean $\mathrm{RI}$ left/right in healthy controls $0.6 \pm 0.045, p=0.001$ ) were significantly higher in children with type 1 diabetes, particularly in those who had additionally been diagnosed with insulin resistance syndrome, hypertension or obesity. The authors concluded that these doppler parameters should be added to the routine workup in diabetic children, especially with these additional risk factors, as they could potentially help diagnose diabetic nephropathy before the appearance of albuminuria. This study also shows that the results obtained through PI measurements may also be supported by other parameters - in this specific case, resistivity index [43].

Sawires et al. have also suggested PI as one of the Doppler markers of renal dysfunction in children. They have shown a significant difference in PI $(p=0.02)$, amongst other tested parameters, when comparing a group of 42 children with chronic kidney disease (1.05 \pm 0.36$)$ with 42 healthy controls $(0.89 \pm 0.23)$ [44]

Additionally, $\mathrm{PI}$ in children appears to have several applications in Pediatric Neurology. A study from 2015 suggests that PI could be used as a simple, non-invasive method of assessing raised intracranial pressure in children who are at risk but do not meet all the criteria for invasive monitoring. The PI measured at the middle cerebral artery had good specificity and sensitivity in predicting increased intracranial pressure in children with early acute brain injury [45].

\section{Pulsatility index and thyroid disease}

Hypothyroidism, which affects between $4-10 \%$ of the population, is known to have many negative effects on the cardiovascular system. It is associated with impaired relaxation of the vascular smooth muscle and release of nitric oxide, arterial stiffness and increased vascular resistance. It also impacts the renal-angiotensin-aldosterone system, as hepatic renin synthesis is stimulated by triiodothyronine. Additionally, it has a strong effect on lipid metabolism, resulting in elevated total cholesterol, LDL and apolipoprotein B [46].

Ultrasonography of the thyroid gland is one of the most common tests performed in diagnosing thyroid disease. The thyroid arteries, although significantly smaller than the main pulsatile arteries of the cardiovascular system, such as the aorta, the carotid arteries or the renal arteries, still play a significant role in diagnostics. Thus, several studies have investigated the use of measuring the pulsatility index in thyroid vessels.

A study from 2018 evaluated a large group of 208 patients with a mean age of 37.7 years to establish the mean values in euthyroid adults of pulsatility index, along with RI and PSV, of the superior thyroid arteries in euthyroid adults. The mean PI obtained in this study was $0.93 \pm 0.31$, and no significant differences were found between males and females [47].

A case-control study from 2015 investigated carotid artery hemodynamics and cardiovascular risk factors in 31 women with Hashimoto thyroiditis on levothyroxine treatment and 26 euthyroid women with Hashimoto thyroiditis without levothyroxine treatment. They measured carotid intima-media thickness, carotid extra-media thickness and pulsatility indexes in the common carotid artery and internal carotid artery. PI CCA and PI ICA were both increased in the study group when compared to the controls ( $p=0.02$ and $p=0.047$ ), while CIMT and CEMT were similar in both groups. The authors concluded, that it was the hormonal imbalance of hypothyroidism that influences arterial stiffness, and not the autoimmune disease process itself, that causes arterial stiffness [48]. In a more recent study by Kalantari [49], he investigated the use of color doppler and gray scale ultrasound on predicting thyroid nodule malignancy. All of the 63 participants had a thyroid ultrasound done, which was followed by fine-needle aspiration and surgery. Out of the doppler parameters obtained in this study, pulsatility index was the most predictive factor of thyroid malignancy, with a positive predictive value (PPV) of $62 \%$ and a negative predictive value (NPV) of $100 \%$. The author concluded that a combination of the presence of calcifications, a resistive index at or above 0.715 and $\mathrm{P} \mathrm{PI}$ at or above 0.945 was strongly diagnostic of malignancy (PPV $=66.6 \%$, NPV 98.4\%).

\section{Pulsatility index as a marker of brain edema}

Published reports indicate that increased flow pulsatility in main cerebral arteries may reflect raised intracranial pressure (ICP) in brain edema. Asil et al [50] showed that in patients with ICP progression in malignant middle cerebral artery (MCA) infarction the pulsatility indices of MCA were higher on the third hospital day than on the first day, and PI were correlated with the midline shift measured on the third day after stroke. They also showed worse prognoses in patients with $\mathrm{PI}>1.5$ than $\mathrm{PI}<1.5$. Bor-Seng-Shu [51] reported that PI values decrease significantly after decompressive craniectomy. On the other hand, some authors indicate, 
that PI-based methods can not predict ICP reliably, as some studies show poor or inexistent correlations between both parameters. Nevertheless, flow spectra analysis with the use of Transcranial Doppler is applied as a supportive method in the procedure of the brain death confirmation [50,52] (Fig. 3, Tab. 1).

\section{Conclusion}

Based on our extensive review of the literature and the gathered information, we conclude that pulsatility index $(\mathrm{PI})$ is an easy to obtain parameter with a broad range of both, research and clinical applications. It has been widely used in the assessment of macrocirculation in highly prevalent chronic medical conditions, such as hypertension, both type 1 and type 2 diabetes and thyroid disorders. For instance, in diabetic patients, it has been found to be of great value in prediction and early diagnosis of microvascular complications.

Amongst the cited articles, PI has mainly been measured at carotid arteries and middle cerebral arteries, but also at renal arteries, peripheral limb vasculature or thyroid vessels. Because it is non-invasive and requires

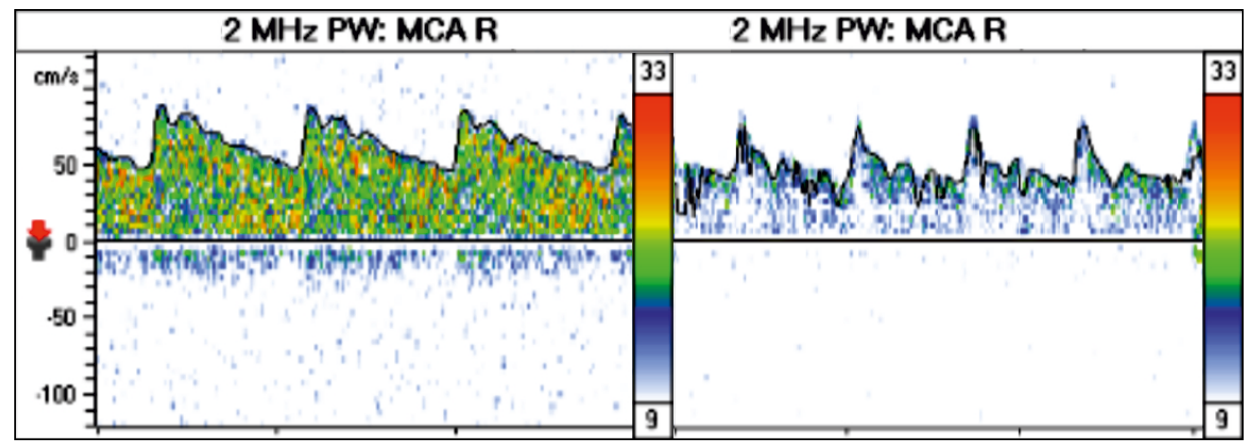

Figure 3. Transcranial Doppler examination of Middle Cerebral Artery. Left picture — normal flow with low pulsatility (PI 0,62 ); right picture - increased pulsatility (PI 1,18) due to raised intracranial pressure (Exam performed Laboratory of Neurosonology, Department of Neurology, Collegium Medicum in Bydgoszcz, Nicolaus Copernicus University in Toruń, head of the clinic dr. hab. G. Kozera, using a Viasys Companion III camera with a PW $2 \mathrm{MHz}$ probe

Table 1. Clinical applications of Pulsatility Index (PI)

\begin{tabular}{|c|c|c|c|}
\hline $\begin{array}{l}\text { Clinical } \\
\text { application }\end{array}$ & Reference/year & Study group & Method and study area \\
\hline $\begin{array}{l}\text { Hypertension and } \\
\text { heart disease }\end{array}$ & Cho $[14] / 1997$ & $\begin{array}{l}94 \text { stroke-free, hypertensive patients } \\
\text { divided into two groups based on } \\
\text { hypertension duration and controls, } 81 \text { y }\end{array}$ & $\begin{array}{l}\text { PI in middle cerebral artery/internal carotid } \\
\text { artery }\end{array}$ \\
\hline
\end{tabular}

Bardelli [16]/1992 49 hypertensive patients, with and without $\mathrm{PI}$ in renal arteries renal artery stenosis, and 20 normotensive controls

Petersen [17]/1995 25 hypertensive patients with a GFR of $<\quad \mathrm{PI}$ and RI in renal arteries $50 \mathrm{~mL} / \mathrm{min}$ and blood pressure $>140 / 95$, and 10 healthy, normotensive volunteers

Okura [18]/2004 51 patients with essential hypertension

Intrarenal PI and resistive index, carotid intimal-media thickness

Sasaki [19]/2019 1313 participants 70 years or older without $\mathrm{PI}$ and resistance index in Common carotid cardiovascular disease. artery, log NT-pro-BNP levels

Atherosclerosis

Jotoku [21]/2015

67 hypertensive patients

$\mathrm{PI}$ in common carotid artery, homocysteine and arterial stenosis

Heyer [23]/2014

53 patients who underwent carotid artery and monocyte levels endarectomy

Wada [24]/2019 42 patients with intracranial vertebral artery PI in carotid ultrasonography dissection

Cay [25]/2010 45 patients with aortic stenosis / 45 healthy Fractional pulse pressure (FFP) and $\mathrm{PI}$ at controls the ascending aorta 
Table 1. cont. Clinical applications of Pulsatility Index (PI)

\begin{tabular}{|c|c|c|c|}
\hline $\begin{array}{l}\text { Clinical } \\
\text { application }\end{array}$ & Reference/year & Study group & Method and study area \\
\hline \multirow[t]{12}{*}{$\begin{array}{l}\text { Vascular } \\
\text { malformations }\end{array}$} & Burkhardt [27]/2015 & $\begin{array}{l}32 \text { patients with arteriovenous } \\
\text { malformations (AVMs) }\end{array}$ & $\begin{array}{l}\mathrm{PI} \text { and } \mathrm{RI} \text { measured on AVM feeding } \\
\text { arteries }\end{array}$ \\
\hline & Kaspera [28]/2014 & 46 adult patients diagnosed with AVMs & PI in the embolized feeding vessels \\
\hline & Fukuhara [32]/2006 & $\begin{array}{l}159 \text { patients hospitalized for controlling } \\
\text { type } 2 \text { diabetes mellitus }\end{array}$ & $\mathrm{PI}$ at the internal carotid artery \\
\hline & Soyoye [12]/2018 & 80 adults with type 2 diabetes mellitus & $\mathrm{Pl}$ in renal artery \\
\hline & Lee $[33] / 2000$ & $\begin{array}{l}56 \text { type } 2 \text { diabetic patients with a mean age } \\
\text { of } 59 \text {, and } 70 \text { age- and gender-matched } \\
\text { healthy controls }\end{array}$ & $\begin{array}{l}\text { PI in middle cerebral artery/internal carotid } \\
\text { artery }\end{array}$ \\
\hline & Agha [34]/2014 & $\begin{array}{l}141 \text { diabetic patients and } 131 \text { sex and age- } \\
\text { matched controls }\end{array}$ & $\begin{array}{l}\mathrm{PI} \text { and flow velocity at middle cerebral, } \\
\text { basilar and intracranial portion of the } \\
\text { internal carotid artery }\end{array}$ \\
\hline & Park [35]/2008 & $\begin{array}{l}90 \text { patients with stroke-free type } 2 \text { diabetes } \\
\text { and } 45 \text { healthy age- and sex-matched } \\
\text { controls }\end{array}$ & $\mathrm{PI}$ in middle cerebral artery \\
\hline & Kozera [36]/2019 & $\begin{array}{l}51 \text { patients with type } 1 \text { diabetes mellitus, } \\
\text { with a median age of } 37.5 \text { years }\end{array}$ & PI in middle cerebral artery \\
\hline & Kozera [37]/2010 & $\begin{array}{l}54 \text { men with hypertension, all } 60 \text { years of } \\
\text { age }\end{array}$ & $\begin{array}{l}\mathrm{PI} \text { in middle cerebral artery, Magnetic } \\
\text { resonance imaging }\end{array}$ \\
\hline & Janssen [38]/2005 & $\begin{array}{l}106 \text { diabetic patients who presented with } \\
\text { polyneuropathy }\end{array}$ & $\begin{array}{l}\text { PI in ankle artery, digital subtraction } \\
\text { arteriography, ankle-brachial Doppler } \\
\text { index, systolic ankle blood pressure }\end{array}$ \\
\hline & Zou [13] /2017 & $\begin{array}{l}56 \text { type } 2 \text { diabetic patients and } 50 \text { healthy } \\
\text { controls }\end{array}$ & $\begin{array}{l}\mathrm{Pl} \text { and } \mathrm{RI} \text { at the dorsalis pedis artery and } \\
\text { plantar digital artery, a warm bath test }\end{array}$ \\
\hline & Park [40]/2007 & $\begin{array}{l}40 \text { type } 2 \text { diabetic patients divided into two } \\
\text { groups: one treated with pioglitazone, one } \\
\text { treated with gliclazide }\end{array}$ & $\begin{array}{l}\mathrm{Pl} \text { in middle cerebral artery and basilar } \\
\text { artery, carotid intima-media thickness }\end{array}$ \\
\hline \multirow[t]{4}{*}{ Pediatrics } & Schoning [41]/1998 & $\begin{array}{l}48 \text { adults, } 94 \text { healthy children and } \\
\text { adolescents }\end{array}$ & PI in common carotid artery \\
\hline & $\begin{array}{l}\text { Abd El Ghaffar } \\
{[43] / 2010}\end{array}$ & $\begin{array}{l}100 \text { diabetic children, aged } 13.4 \pm 2.9, \\
\text { with an average diabetes duration } 7.2 \pm \\
2.5 \text { years, and } 30 \text { healthy controls }\end{array}$ & Renal PI and $\mathrm{RI}$ \\
\hline & Sawires [44]/2018 & $\begin{array}{l}42 \text { children with chronic kidney disease } \\
\text { and } 42 \text { healthy controls }\end{array}$ & $\mathrm{PI}$ in renal arteries \\
\hline & O'Brian [45]/2020 & $\begin{array}{l}36 \text { children admitted to intensive care units } \\
\text { with a diagnosis of severe traumatic brain } \\
\text { injury }(\mathrm{GCS}=<8)\end{array}$ & PI in middle cerebral artery \\
\hline \multirow[t]{3}{*}{ Thyroid disease } & Joish [47]/2018 & 208 patients with a mean age of 37.7 & $\mathrm{PI}, \mathrm{RI}$ and $\mathrm{PSV}$ of the superior thyroid artery \\
\hline & Owecki [48]/2015 & $\begin{array}{l}31 \text { women with Hashimoto thyroiditis on } \\
\text { levothyroxine treatment and } 26 \text { euthyroid } \\
\text { women with Hashimoto thyroiditis without } \\
\text { levothyroxine treatment. }\end{array}$ & $\begin{array}{l}\mathrm{PI} \text { in common carotid artery and } \mathrm{PI} \text { in } \\
\text { internal carotid artery }\end{array}$ \\
\hline & Kalantari [49] /2018 & 63 patients with thyroid nodules. & $\mathrm{PI}$ and $\mathrm{RI}$ at thyroid nodules \\
\hline \multirow[t]{2}{*}{ Brain edema } & Asil [50]/2003 & $\begin{array}{l}18 \text { patients with first-ever strokes and large } \\
\text { MCA (middle cerebral artery) infarction }\end{array}$ & $\mathrm{PI}$ in middle cerebral artery \\
\hline & $\begin{array}{l}\text { Bor-Sheng-Shu } \\
{[51] / 2013}\end{array}$ & $\begin{array}{l}19 \text { patients presenting with traumatic brain } \\
\text { swelling }\end{array}$ & PI in transcranial ultrasonography \\
\hline
\end{tabular}


little cooperation, it has also been widely used in pediatric populations. In pediatric patients with diabetes, it has been shown to aid with diagnoses of renal damage prior to the development of microalbuminuria. In the emergency room setting, it has been suggested as a useful tool in assessing raised intracranial pressure in patients with acute head trauma [45]. It may also serve as an indirect sign of distal pathology in the assessed vascular bed in case of stenosis (where the PI value increases) and widening (where the PI value decreases). Thus, it may indicate the necessity of further evaluation of distal segments that are not easily accessible with ultrasound techniques.

$\mathrm{PI}$ has the potential to be used in the assessment of disease progression and treatment efficacy. It has been suggested to have value in assessing the severity of calcific aortic stenosis [25], while in hypertensive patients it has been demonstrated to correlate with disease duration [14]. It was also used to determine the effect of pioglitazone therapy on cerebrovascular resistance in diabetic patients [40].With this article, we would like to encourage wider use of pulsatility index, and demonstrate the clinical areas in which there is potential for more research with the use of this doppler parameter. $\mathrm{PI}$ is non-invasive, inexpensive and, when used skillfully, may be extremely helpful in diagnosing a variety of complex vascular pathologies.

Statement of competing interests: The authors declared no potential conflicts of interest with respect to the research, authorship, and/or publication of this article.

\section{References}

1. Tocci G, Sciarretta S, Volpe M. Development of heart failure in recent hypertension trials. Journal of Hypertension. 2008; 26(7): 1477-1486, doi: 10.1097/hjh.0b013e3282fe1d3d.

2. Roper NA, Bilous RW, Kelly WF, et al. Cause-Specific Mortality in a Population With Diabetes: South Tees Diabetes Mortality Study. Diabetes Care. 2002; 25(1): 43-48, doi: 10.2337/diacare.25.1.43

3. Bebu I, Schade D, Braffett B, et al. Risk Factors for First and Subsequent CVD Events in Type 1 Diabetes: The DCCT/EDIC Study. Diabetes Care. 2020; 43(4): 867-874, doi: 10.2337/dc19-2292.

4. Einarson T, Acs A, Ludwig C, et al. Prevalence of cardiovascular disease in type 2 diabetes: a systematic literature review of scientific evidence from across the world in 2007-2017. Cardiovascular Diabetology. 2018; 17(1), doi: 10.1186/s12933-018-0728-6.

5. Graves L, Donaghue K. Management of diabetes complications in youth. Therapeutic Advances in Endocrinology and Metabolism. 2019; 10: 204201881986322, doi: 10.1177/2042018819863226.

6. Climie R, Gallo A, Picone D, et al. Measuring the Interaction Between the Macro- and Micro-Vasculature. Frontiers in Cardiovascular Medicine. 2019; 6, doi: 10.3389/fcrm.2019.00169.

7. Gosling RD, King DH. Arterial assessment by Doppler-shift Ultrasound. Proc R Soc Med. 1974; 67(6 Pt 1): 447-449.

8. Barić D. Why pulsatility still matters: a review of current knowledge. Croatian Medical Journal. 2014; 55(6): 609-620, doi: 10.3325/cmi.2014.55.609.

9. Hussein A, Brunozzi D, Shakur S, et al. Cerebral Aneurysm Size and Distal Intracranial Hemodynamics: An Assessment of Flow and Pulsatility Index Using Quantitative Magnetic Resonance Angiography. Neurosurgery. 2017; 83(4): 660-665, doi: 10.1093/neuros/nyx441.

10. Hussein $A$, Esfahani $D$, Linninger $A$, et al. Aneurysm size and the Windkessel effect: An analysis of contrast intensity in digital subtraction angiography. Interventional Neuroradiology. 2017; 23(4): 357-361, doi: 10.1177/1591019917701100

11. Kassab MY, Majid A, Farooq MU, et al. Transcranial Doppler An Introduction for Primary Care Physicians. The Journal of the American Board of Family Medicine. 2007; 20(1): 65-71, doi: 10.3122/jabfm.2007.01.060128

12. Soyoye DO, Dawha SD, Ayoola OO, et al. Relationship between Renal Doppler Indices and Biochemical indices of Renal Function in Type 2 Diabetes Mellitus. West Afr J Med. 2018; 35(3): 189-194.

13. Zou C, Jiao Y, Li X, et al. Differences between healthy adults and patients with type 2 diabetes mellitus in reactivity of toe microcirculation by ultrasound combined with a warm bath test. Medicine. 2017; 96(22): e7035, doi: 10.1097/md.0000000000007035.

14. Cho S, Sohn Y, Kim G, et al. Blood flow velocity changes in the middle cerebral artery as an index of the chronicity of hypertension. Journal of the Neurological Sciences. 1997; 150(1): 77-80, doi: 10.1016/s0022$-510 \times(97) 05391-4$.

15. Mitchell G. Aortic stiffness, pressure and flow pulsatility, and target organ damage. Journal of Applied Physiology. 2018; 125(6): 1871-1880, doi: 10.1152/japplphysiol.00108.2018.

16. Bardelli $M$, Jensen $G$, Volkmann $R$, et al. Non-invasive ultrasound assessment of renal artery stenosis by means of the Gosling pulsatility index. Journal of Hypertension. 1992; 10(9): 985???990, doi: 10.1097/00004872-199209000-00011

17. Petersen LJ, Petersen JR, Ladefoged SD, et al. The pulsatility index and the resistive index in renal arteries in patients with hypertension and chronic renal failure. Nephrol Dial Transplant. 1995; 10(11): 2060-2064.

18. Okura T. Intrarenal and carotid hemodynamics in patients with essential hypertension. American Journal of Hypertension. 2004; 17(3): 240-244, doi: 10.1016/j.amjhyper.2003.10.005.

19. Sasaki N, Yamamoto H, Ozono R, et al. Association of Common Carotid Artery Measurements with N-terminal Pro B-type Natriuretic Peptide in Elderly Participants. Internal Medicine. 2020; 59(7): 917-925, doi: 10.2169/internalmedicine.3780-19.

20. Avrahami I, Kersh D, Liberzon A. Pulsatility Index as a Diagnostic Parameter of Reciprocating Wall Shear Stress Parameters in Physiological Pulsating Waveforms. PLOS ONE. 2016; 11(11): e0166426, doi: 10.1371/journal.pone.0166426.

21. Jotoku M, Okura T, Miyoshi Ki, et al. Carotid hemodynamics is associated with monocyte count determined by serum homocysteine level in patients with essential hypertension. Clinical and Experimental Hypertension. 2014; 37(5): 358-363, doi: 10.3109/10641963.2014.972563.

22. Norouzpour A, Hooshyar Z, Mehdizadeh A. Autoregulation of blood flow: Vessel diameter changes in response to different temperatures. $J$ Biomed Phys Eng. 2013; 3(2): 63-6.

23. Heyer E, Mergeche J, Connolly E. Middle cerebral artery pulsatility index and cognitive improvement after carotid endarterectomy for symptomatic stenosis. Journal of Neurosurgery. 2014; 120(1): 126-131, doi: 10.3171/2013.8.jns13931.

24. Wada S, Koga M, Makita N, et al. Detection of Stenosis Progression in Intracranial Vertebral Artery Dissection Using Carotid Ultrasonography. Journal of Stroke and Cerebrovascular Diseases. 2019; 28(8) 2201-2206, doi: 10.1016/j.jstrokecerebrovasdis.2019.04.033.

25. Cay S, Cagirci G, Atak R, et al. Ascending aortic pressure-derived indices are associated with the presence and severity of aortic stenosis. Blood Pressure. 2010; 19(1): 48-53, doi: 10.3109/08037050903312804.

26. Bartels E. Evaluation of Arteriovenous Malformations (AVMs) With Transcranial Color-Coded Duplex Sonography. Journal of Ultrasound in Medicine. 2005; 24(11): 1511-1517, doi: 10.7863/jum.2005.24.11.1511.

27. Burkhardt T, et al. Siasios G Schmidt NO Intraoperative Micro-Doppler in Cerebral Arteriovenous Malformations. J Neurol Surg A Cent Eur Neurosurg. 2015; 76(6): 451-5

28. Kaspera W, Ładziński P, Larysz $P$, et al. Transcranial color-coded Doppler assessment of cerebral arteriovenous malformation hemodynamics in patients treated surgically or with staged embolization. Clinical Neurology and Neurosurgery. 2014; 116: 46-53, doi: 10.1016/j. clineuro.2013.11.001

29. Center for Disease Control and Prevention, section on type. https:// www.cdc.gov/diabetes/basics/type2.html.

30. Dec-Gilowska M, Trojnar M, Makaruk B, et al. Circulating Endothelial Microparticles and Aortic Stiffness in Patients with Type 2 Diabetes Mellitus. Medicina. 2019; 55(9): 596, doi: 10.3390/medicina55090596.

31. Climie R, Picone D, Blackwood S, et al. Pulsatile interaction between the macro-vasculature and micro-vasculature: proof-of-concept among patients with type 2 diabetes. European Journal of Applied Physiology. 2018; 118(11): 2455-2463, doi: 10.1007/s00421-0183972-2. 
32. Fukuhara T, Hida K. Pulsatility Index at the Cervical Internal Carotid Artery as a Parameter of Microangiopathy in Patients With Type 2 Diabetes. Journal of Ultrasound in Medicine. 2006; 25(5): 599-605 doi: 10.7863/jum.2006.25.5.599.

33. Lee K, Sohn Y, Baik J, et al. Arterial Pulsatility as an Index of Cerebra Microangiopathy in Diabetes. Stroke. 2000; 31(5): 1111-1115, doi 10.1161/01.str.31.5.1111.

34. Agha MS, Alboudi A. Arterial Pulsatility as an index of cerebral microangiopathy in diabetes type 2. 2014; 19(3): 198-203.

35. Park J, Cho M, Lee K, et al. Cerebral arterial pulsatility and insulin resistance in type 2 diabetic patients. Diabetes Research and Clinica Practice. 2008; 79(2): 237-242, doi: 10.1016/j.diabres.2007.08.029.

36. Kozera G, Neubauer-Geryk J, Wolnik B, et al. Cerebral and skin microcirculatory dysfunction in type 1 diabetes. Advances in Dermatology and Allergology. 2019; 36(1): 44-50, doi: 10.5114/ada.2018.81185.

37. Kozera G, Dubaniewicz M, Zdrojewski T, et al. Cerebral Vasomoto Reactivity and Extent of White Matter Lesions in Middle-Aged Men With Arterial Hypertension: A Pilot Study. American Journal of Hypertension. 2010; 23(11): 1198-1203, doi: 10.1038/ajh.2010.152

38. Janssen A. Pulsatility index is better than ankle-brachial doppler index for non-invasive detection of critical limb ischaemia in diabetes. Vasa 2005; 344: 235-241.

39. Cheng SH, Wang J, Xu GH, et al. Effect of Noaxintong Capsule on Vascular Remodelin in Type 2 Diabetic Patients with Subclinical Vascular Disease. Zhongguo Zhong Xi Yi Jie He Za Zhi. 2016; 36(12) 1439-1444.

40. Park J, Cho M, Lee K, et al. The effects of pioglitazone on cerebrovascular resistance in patients with type 2 diabetes mellitus. Metabolism 2007; 56(8): 1081-1086, doi: 10.1016/j.metabol.2007.03.017.

41. Schöning M, Hartig B. The development of hemodynamics in the extracranial carotid and vertebral arteries. Ultrasound in Medicine \& Biology. 1998; 24(5): 655-662, doi: 10.1016/s03015629(98)00029-5.

42. Schöning M, Walter J, Scheel P. Estimation of cerebral blood flow through color duplex sonography of the carotid and vertebral arteries in healthy adults. Stroke. 1994; 25(1): 17-22, doi: 10.1161/01.str.25.1.17.
43. Ghaffar SA, Kaffas KEl, Hegazy R, et al. Renal Doppler indices in diabetic children with insulin resistance syndrome. Pediatric Diabetes. 2010; 11(7): 479-486, doi: 10.1111/j.1399-5448.2009.00628.x.

44. Sawires H, Salah D, Hashem R et al. Renal ultrasound and Doppler parameters as markers of renal function and histopathological damage in children with chronic kidney disease. Nephrology. 2018; 23(12): 1116-1124, doi: 10.1111/nep.13201.

45. O'Brien N, Maa T, Reuter-Rice K. Noninvasive screening for intracranial hypertension in children with acute, severe traumatic brain injury. Journal of Neurosurgery: Pediatrics. 2015; 16(4): 420-425, doi: 10.3171/2015.3. peds14521.

46. Udovcic M, Pena R, Patham B, et al. Hypothyroidism and the Heart. Methodist DeBakey Cardiovascular Journal. 2017; 13(2): 55-59, doi: 10.14797/mdcj-13-2-55

47. Kavitha $Y$, Joish $U$, Reddy $R$, et al. Doppler indices of superior thyroid artery in clinically euthyroid adults. Indian Journal of Radiology and Imaging. 2018; 28(1): 10, doi: 10.4103/ijri.jiri 19417.

48. Owecki M, Sawicka-Gutaj N, Owecki M, et al. Pulsatility Index in Carotid Arteries is Increased in Levothyroxine-Treated Hashimoto Disease. Hormone and Metabolic Research. 2015; 47(08): 577-580, doi: 10.1055/s-0034-1398491.

49. Kalantari S. The Diagnostic Value of Color Doppler Ultrasonography in Predicting Thyroid Nodules Malignancy. The International Tinnitus Journal. 2018; 22(1), doi: 10.5935/0946-5448.20180006.

50. Asil T, Uzunca I, Utku U, et al. Monitoring of Increased Intracranial Pressure Resulting From Cerebral Edema With Transcranial Doppler Sonography in Patients With Middle Cerebral Artery Infarction. Journal of Ultrasound in Medicine. 2003; 22(10): 1049-1053, doi: 10.7863/jum.2003.22.10.1049.

51. Bor-Seng-Shu E, Figueiredo E, Fonoff E, et al. Decompressive craniectomy and head injury: brain morphometry, ICP, cerebral hemodynamics, cerebral microvascular reactivity, and neurochemistry. Neurosurgical Review. 2013; 36(3): 361-370, doi: 10.1007/s10143-013-0453-2.

52. Obwieszczenie Ministra Zdrowia z dnia 4 grudnia 2019 r w sprawie sposobu i kryteriów stwierdzenia trwałego nieodwracalnego ustania czynności mózgu. 